\title{
Agonists of proteinase-activated receptor-2 affect transendothelial migration and apoptosis of human neutrophils
}

\author{
Victoria M. Shpacovitch ${ }^{1 *}$, Stephan Seeliger ${ }^{{ }^{*}}$, Markus Huber-Lang ${ }^{2}$, Sandra Balkow ${ }^{1}$, Micha Feld $^{1}$, \\ Morley D. Hollenberg ${ }^{3}$, Vidya J. Sarma ${ }^{4}$, Peter A. Ward ${ }^{4}$, Anke Strey ${ }^{5}$, Volker Gerke ${ }^{5}$, Christian P. \\ Sommerhoff $^{6}$, Nathalie Vergnolle ${ }^{3}$ and Martin Steinhoff ${ }^{1}$ \\ ${ }^{1}$ Department of Dermatology, IZKF Münster, and Boltzmann Institute for Immunobiology of the Skin, University of Münster, Germany; \\ ${ }^{2}$ Department of Traumatology, University of Ulm, Ulm, Germany; \\ ${ }^{3}$ Canadian Institutes of Health Research Proteinases and Inflammation Network, Department of Pharmacology and Therapeutics, University of \\ Calgary, Calgary, AB, Canada; \\ ${ }^{4}$ Department of Pathology, University of Michigan Medical School, Ann Arbor, MI, USA; \\ ${ }^{5}$ Institute of Biochemistry, ZMBE, University of Münster, Münster, Germany; \\ ${ }^{6}$ Department of Clinical Chemistry and Clinical Biochemistry, University of München, München, Germany \\ Correspondence: Victoria M. Shpacovitch, PhD, Laboratory of Cell Biology, Department of Dermatology, University of Münster, Von-Esmarch-Str. \\ 58, 48149 Münster, Germany, Tel.: +49 (0) 25183 56598, Fax: +49 (0) 25183 57452, e-mail: shpacovi@ukmuenster.de \\ ${ }^{\star}$ These authors contributed equally to this work.
}

Accepted for publication 19 June 2007

\begin{abstract}
Skin is the first barrier preventing microorganism invasion in host. Wounds destroy this defense barrier and, without an appropriate care, may lead to sepsis. Neutrophil activation and immigration plays an important role at the inflammatory stage of wound healing. Neutrophils are known to express proteinase-activated receptors (PARs), which can be activated by serine proteases, also by enzymes involved in wound healing. We previously reported that $\mathrm{PAR}_{2}$ agonists up-regulate cell adhesion molecule expression and cytokine production by human neutrophils. Here, we demonstrate that $\mathrm{PAR}_{2}$ agonists (serine proteases as well as synthetic peptides) reduce transendothelial migration of neutrophils and prolong their life in vitro. Synthetic $\mathrm{PAR}_{2}$ agonist also enhanced protective interferon (IFN) $\gamma$-induced Fc $\gamma$ RI expression at neutrophil cell
\end{abstract}

surface. Of note, IFN $\gamma$ is a cytokine, which was used in clinical trials to reactivate human neutrophil functions during sepsis. Moreover, we observed a significant increase of $\mathrm{PAR}_{2}$ expression on cell surface of neutrophils from septic patients as compared with healthy volunteers. Together, our results indicate that $\mathrm{PAR}_{2}$ may be involved in the pathophysiology of neutrophil-endothelial interactions during wound healing or later during sepsis in humans, potentially by affecting neutrophil apoptosis, transendothelial migration and $\mathrm{F} c \gamma$ receptor-mediated phagocytosis.

Key words: inflammation - innate immunity - leukocyte proteinase-activated receptor - skin

Please cite this paper as: Agonists of proteinase-activated receptor-2 affect transendothelial migration and apoptosis of human neutrophils. Experimental Dermatology 2007; 16: 799-806.

\section{Introduction}

Proteinase-activated receptor-2 $\left(\mathrm{PAR}_{2}\right)$ is the second member of a novel $G$ protein-coupled receptor subfamily with a unique mechanism of receptor activation. Accessible serine

Abbreviations: FCS, fetal calf serum; fMLP, $N$-formylmethionylleucyl-phenylalanine; HMEC-1, human microvascular endothelial cells; HUVEC, human umbilical vein endothelial cells; IFN $\gamma$, interferon gamma; $\mathrm{PAR}_{2}$, proteinase-activated receptor-2; $\mathrm{PMN}$, polymorphonuclear neutrophil; tcAP, tc-activating peptide; tcRP, tc-reverse peptide. proteases cleave the receptor to expose a new, previously cryptic, N-terminal sequence, which serves further as a 'tethered' receptor-activating ligand. To date, four PARs are known [reviewed in Refs. $(1,2)$ ]. A variety of serine proteinases, including members of the trypsin family, mast cell tryptase, immune cell-derived or microorganismderived enzymes activate $\mathrm{PAR}_{2}(3-8)$. Functional $\mathrm{PAR}_{2}$ is expressed by cells involved in inflammatory and allergic responses such as mast cells, dendritic cells, eosinophils, macrophages and neutrophils (9-14). However, the ability of $\mathrm{PAR}_{2}$ agonists to act on key neutrophil features such as phagocytosis, apoptosis or transmigration through the 
endothelium is still uninvestigated. Nonetheless, $\mathrm{PAR}_{2}$ immunoreactivity can be found on neutrophils during inflammation or delayed wound healing, for example. Thus, $\mathrm{PAR}_{2}$ may be involved in wound healing (inflammatory stage) or in further progression of inflammation of untreated wounds, which in very serious cases leads to sepsis.

Recent studies indicated an important role for $\mathrm{PAR}_{2}$ activation in the development of arthritis, acute pancreatitis, airway inflammation, atopic dermatitis, and encephalomyelitis $(2,15,16)$. In some cases, $\mathrm{PAR}_{2}$ activation led to pro-inflammatory effects (17-19), however, under certain conditions to anti-inflammatory protective effects $(20,21)$. Changes in main neutrophil functions are known to play a role in bacteria-induced pathologies (wound infection, sepsis or septic shock) as well as in bacteria-induced complications of skin diseases $(22,23)$. However, the role of $\mathrm{PAR}_{2}$ activation in modulation of neutrophil-endothelial interaction and neutrophil apoptosis during such diseases remains elusive.

Interferons (IFN $\gamma, \operatorname{IFN} \alpha$ ) are known to activate protective functions of human neutrophils and monocytes (phagocytosis, generation of reactive oxygen species, bacterial killing) (24-27). IFN $\gamma$ was also used in clinical trials in sepsis for reactivation of monocyte and neutrophil immune functions (28). However, the ability of $\mathrm{PAR}_{2}$ agonists to enhance (during combined application) IFN $\gamma$-induced protective effects at human neutrophils is still unclear.

Previously (29), we demonstrated that $\mathrm{PAR}_{2}$ agonists up-regulate the expression of $\alpha_{4} \beta_{1}$ and Mac-1 integrins on neutrophil cell surface, and also enhance the production of IL- $1 \beta$, IL-6, IL-8 by human neutrophils (29). These integrins and cytokines are known to affect neutrophil transendothelial migration, apoptosis and phagocytic activity [reviewed in Refs. (30,31)]. Therefore, we hypothesized that stimulation of human neutrophils with $\mathrm{PAR}_{2}$ agonists may act on such key neutrophil features in vitro. To explore this, we examined whether $\mathrm{PAR}_{2}$ agonists affect: (i) human neutrophil apoptosis and (ii) neutrophil transendothelial migration. Further, we investigated the ability of $\mathrm{PAR}_{2}$ agonist to enhance IFN $\gamma$-induced protective effect at human neutrophils (expression of Fc $\gamma$-receptors, which are known to play crucial role in phagocytic activity of these cells). Moreover, we determined whether neutrophils of septic patients show altered $\mathrm{PAR}_{2}$ cell surface expression as compared with cells from healthy volunteers.

\section{Materials and methods}

\section{Reagents}

Human recombinant interferon- $\gamma($ IFN $\gamma)$ was obtained from TebuBio (Offenbach, Germany). Trypsin was purchased from Sigma (Deisenhofen, Germany). Human $\beta$-tryptase was expressed in Pichia pastoris and used as described (32). Human $\mathrm{PAR}_{2}$ activating peptide with the sequence trans-cinnamoyl-LIGRLO-NH $\mathrm{H}_{2}$ (tcAP) and reverse peptide with sequence trans-cinnamoyl-OLRGIL-NH $\mathrm{H}_{2}$ (tcRP) (Dr. McMaster, University of Calgary, Canada) was used as described previously $(29,33)$. Primary antibodies were: unconjugated or fluorescein isothiocyanate (FITC)-conjugated monoclonal mouse anti-human $\mathrm{PAR}_{2}$ (clone SAM-11) (Santa Cruz Biotechnology, Heidelberg, Germany); monoclonal mouse anti-human CD64 (DakoCytomation, Hamburg, Germany) and secondary antibodies were PE-conjugated goat anti-mouse from Jackson ImmunoResearch (Hamburg, Germany). The FITC-conjugated mouse $\mathrm{IgG}_{1}$ isotype control antibodies were from PharMingen (Hamburg, Germany). Cell culture reagents were from BioWhittaker (Aachen, Germany), PromoCell (Heidelberg, Germany), Gibco-Life Technologies (Karlsruhe, Germany), Sigma, Beckton-Dickenson (Heidelberg, Germany), Falcon (via Beckton-Dickenson, Heidelberg, Germany), Corning (Schiphool, the Netherlands).

\section{Isolation and culture of human neutrophils}

For sepsis studies, the blood from patients who fulfilled the clinical criteria for septic shock, was used (34). The study of patients with septic shock $(n=19)$ and healthy volunteers ( $n=18$, sex and aged matched) was performed with the permission of the Independent Ethics Committee of the University of Ulm (approval No. 82/2002). Exclusion criteria were age $<18$ years, pregnancy, rapidly progressing underlying disease, HIV/AIDS, cardiogenic shock as the primary underlying disease, underlying haematological disease, or cytotoxic therapy given within the previous 6 months.

Blood for in vitro experiments with normal human neutrophils was obtained from healthy adult human volunteers in heparinized tubes or in buffy-coats (Deutsches Rotes Kreuz, Muenster, Germany). Polymorphonuclear neutrophils (PMNs) were isolated using lymphocyte separation medium (equivalent of Percoll produced by PAA Laboratories, Cölbe, Germany) followed by hypotonic stress to remove erythrocytes, as described $(29,35)$. Neutrophils were cultured in RPMI 1640 medium supplied with: 1\% fetal calf serum (FCS), 1\% penicillin/streptomycin, 1\% L-Glutamine and $1 \%$ non-essential amino acids. After isolation, cells were cultured $\left(37^{\circ} \mathrm{C}, 5 \% \mathrm{CO}_{2}\right)$ during $2 \mathrm{~h}$ for recovery.

For human neutrophil stimulation, IFN $\gamma$ was used at a concentration of $200 \mathrm{U} / \mathrm{ml}$. The same IFN $\gamma$ concentration was used in all co-stimulation experiments (together with the $\mathrm{PAR}_{2}$ agonist). For $\mathrm{PAR}_{2}$ stimulation, $\mathrm{PAR}_{2}$-tcAP was used in a concentration of $1 \times 10^{-4} \mathrm{M}$. This peptide has been previously documented to be an effective and specific $\mathrm{PAR}_{2}$ agonist in $\mathrm{PAR}_{2}$-expressing cells (33), causing effects identical to a 'tethered' ligand agonist like SLIGRL- $\mathrm{NH}_{2}$ 
or SLIGKV-NH $\mathrm{N}_{2}$. The corresponding reverse peptide $\left(\mathrm{PAR}_{2}\right.$-tcRP) also was used in concentration $1 \times 10^{-4} \mathrm{M}$ and served as negative control. Trypsin and tryptase [tryptase was dissolved in heparin solution, with concentration of heparin $30 \mu \mathrm{g} / \mathrm{ml}$ of phosphate-buffered saline (PBS)] were used in concentration of $1 \times 10^{-7} \mathrm{M}$. Stimulation with heparin solution alone ( $30 \mu \mathrm{g}$ heparin per millilitre of PBS) also was used as an additional control.

\section{Transendothelial migration assay}

Transmigration assays were performed as described in details elsewhere (36). Briefly, $2.2 \times 10^{5}$ human microvascular endothelial cells (HMEC)-1 cells were seeded on fibronectin-coated 6.5-mm Transwell filters (Costar, Bodenheim, Germany) with a $5-\mu \mathrm{m}$ pore size, and were grown at $37^{\circ} \mathrm{C}$ and $5 \% \mathrm{CO}_{2}$ to confluence. The integrity of the endothelial monolayer was confirmed by Filipin III (Sigma, cat. 4767) staining followed by fluorescent microscopic investigation, and, in parallel by the measurement of transendothelial electric resistance. After $48 \mathrm{~h}$, medium and non-adherent cells were removed. Immediately, $600 \mu \mathrm{l}$ of assay medium together with chemo-attractant IL-8 $(25 \mathrm{ng} / \mathrm{ml})$ was added to the lower compartment of a twochamber system separated by the Transwell filters. Assay medium consisted of Dulbecco's modified Eagle's medium (PAA Laboratories, Cölbe, Germany) supplemented with $10 \%$ FCS, $25 \mathrm{~mm}$ HEPES, $2 \%$ L-glutamine and $100 \mathrm{U} / \mathrm{ml}$ penicillin/streptomycin. Always the constant number of neutrophils was taken for assay. Neutrophils $\left(2 \times 10^{6}\right.$ cells $)$ in $100-\mu \mathrm{l}$ assay medium together with stimuli were added to the upper chamber, and cells were subsequently incubated for $2 \mathrm{~h}$ at $37^{\circ} \mathrm{C}$ and $5 \% \mathrm{CO}_{2}$. Among stimuli were either $\mathrm{N}$-formylmethionyl-leucyl-phenylalanine (fMLP) (a well-known granulocyte activator, used as a positive control, concentation $5 \mathrm{nM}$ ) or $\mathrm{PAR}_{2}$ agonists (mast cell tryptase $10^{-7} \mathrm{M}$; trypsin $10^{-7} \mathrm{M}$; PAR $_{2}$-tcAP $1 \times 10^{-4} \mathrm{M}$ ) or $\mathrm{PAR}_{2}$ reverse peptide $\left(\mathrm{PAR}_{2}\right.$-tcRP $\left.1 \times 10^{-4} \mathrm{M}\right)$. Experiments were routinely carried out in triplicates.

At the end of the assay, the upper chamber was removed and the migrated neutrophils in the lower compartment were collected and quantified in a Casy TT (Schärfe Instruments, Reutlingen, Germany) or Coulter Counter Z2 (Coulter, Krefeld, Germany). Each sample was made in triplicate. Four independent experiments were performed.

\section{Flow cytometric analysis of CD64 and $\mathrm{PAR}_{2}$ cell surface expression on neutrophils from healthy volunteers and septic patients}

Briefly, $1 \times 10^{6}$ cells from healthy donors were used for each analysis. Cells were washed twice in PBS (1\%FCS) and subsequently incubated with primary mouse antihuman CD64 antibody or with anti-human $\mathrm{PAR}_{2}$ antibody (in both cases $1 \mu \mathrm{g} / \mathrm{ml}$ ) for $30 \mathrm{~min}$ on ice. Then, cells were washed and further incubated with PE-conjugated goat anti-mouse (1:50) secondary antibody in PBS (1\%FCS) for additional $30 \mathrm{~min}$ on ice. Cells, which were incubated with secondary antibody alone served as a negative control. At least 25000 stained cells were analysed with the FACScalibur and Cell Quest Pro Software (Becton Dickinson, Heidelberg, Germany).

For septic patient studies, whole blood was collected in an EDTA-containing syringe and erythrocytes were lysed using $1 \times$ flow cytometric analysis (FACS) lysing solution (BD PharMingen, San Diego, CA, USA). A total of $10 \mu \mathrm{l}$ of FITC-labelled anti-human $\mathrm{PAR}_{2}$ was used for receptor staining at neutrophil surface (20 $\mathrm{min}$ at RT). FITClabelled IgG was added for isotype control (negative control) samples. After washing, the leukocytes were reconstituted in a fixing solution (1\% paraformaldehyde in PBS). The purity of granulocytes was estimated with antiCD45/anti-CD14 (to exclude monocyte contamination among analysed cells). At least 20000 stained neutrophils from each donor in both groups were analysed with the FACScalibur and Cell Quest Pro Software (Becton Dickinson).

\section{Annexin-V staining assay}

Labelling of apoptotic neutrophils with annexin-V-FITC (37) and counterstaining with propidium iodide for necrotic cells (Annexin V-FITC Apoptosis Detection kit, BD PharMingen) were performed according to manufacturer's instructions. Labelled neutrophils were analysed by flow cytometry using FACScalibur and Cell Quest Pro software (Becton Dickinson).

\section{Statistical analysis}

Results are expressed as mean \pm SEM. At least three independent experiments have been performed $(n>3)$. Statistical evaluation was performed by an analysis of variance and Student's $t$-test. Significance was assigned where $P<0.05$.

\section{Results}

Proteinase-activated receptor-2 agonist stimulation reduces the transendothelial migration of human neutrophils in vitro

Neutrophil-endothelial interactions play a crucial role in the pathophysiology of various skin diseases such as infection, neutrophilc vascular disorders (certain subtypes of vasculitis) or wound healing, for example. We demonstrated previously that $\mathrm{PAR}_{2}$ agonist treatment affects surface expression of $\beta_{1}$ and $\beta_{2}$ integrins by human neutrophils (29). Thus, we hypothesized that $\mathrm{PAR}_{2}$ agonist stimulation of endothelial cells as well as granulocytes may influence migratory ability of the latter. To test this 
hypothesis, we used an experimental system where both cell types (granulocytes and HMEC-1 endothelial cells) were exposed to $\mathrm{PAR}_{2}$ agonists during leukocyte migration. We revealed that application of $\mathrm{PAR}_{2}$ activating serine proteases (trypsin or mast cell tryptase) as well as a synthetic $\mathrm{PAR}_{2}$ activating peptide (tcAP) leads to significant reduction in the number of neutrophils migrated via endothelial monolayer in comparison with untreated control (Fig. 1). The magnitude of this effect was very similar for all $\mathrm{PAR}_{2}$ agonists used in study - about $25 \pm 4 \%$ of reduction (the application of fMLP, which was used as positive control, led to $60 \pm 4 \%$ reduction) (Fig. 1). Neither treatment with heparin nor $\mathrm{PAR}_{2}$ reverse peptide (tcRP) resulted in significant changes of neutrophil transendothelial migration (Fig. 1).

\section{Proteinase-activated receptor-2 agonist stimulation prolongs human neutrophil survival in vitro}

Human neutrophils are known to have a relatively short half-life in the circulation [(reviewed in Ref. (30)]. The life span of mature neutrophils may be extended in vitro by incubation with either pro-inflammatory cytokines or with bacterial products (38). Therefore, we investigated whether treatment of isolated human neutrophils with $\mathrm{PAR}_{2}$ agonists might extend neutrophil survival in vitro. Indeed, $\mathrm{PAR}_{2}$-tcAP stimulation of human neutrophils from healthy donors prolonged cell survival (estimated using population

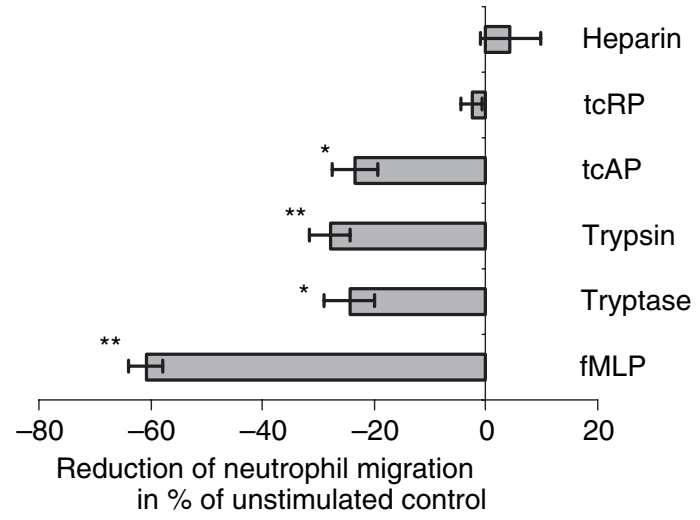

Figure 1. Proteinase-activated receptor-2 $\left(P A R_{2}\right)$ agonists reduce transendothelial migration of human neutrophils from healthy volunteers. The number of granulocytes used for assay (input) was always constant in all experiments and for each sample $\left(2 \times 10^{6}\right.$ cells). The average number of neutrophils migrated in control sample was $5.96 \times 10^{5} \pm 0.8 \times 10^{5}$ cells. In our experimental system, both cell types [human neutrophils and human microvascular endothelial cells (HMEC-1)] were stimulated with $\mathrm{PAR}_{2}$ agonists (see 'Materials and Methods' for details). Stimuli were used in concentrations: tryptase and trypsin $10^{-7} \mathrm{M}$; PAR 2 -tCAP $10^{-4} \mathrm{M}$; PAR 2 -tcRP $10^{-4} \mathrm{M}$; heparin $30 \mu \mathrm{g} / \mathrm{ml}$; $N$-formylmethionyl-leucyl-phenylalanine (fMLP) 5 nм. Four independent experiments were performed, each in triplicates. Results are presented as an average effect of agent application at neutrophil migration (expressed in percents) \pm SEM. ${ }^{*} P<0.05, * * P<0.01$. of early apoptotic cells in Annexin V/propidium-iodide assay) (Fig. 2). At $6 \mathrm{~h}$ after $\mathrm{PAR}_{2}$-tcAP application, the amount of early apoptotic neutrophils was $47 \pm 4 \%$ lower as compared with untreated control cells. However, this trend was still detectable up to $12 \mathrm{~h}$ after agonist treatment. Moreover, application of trypsin in a concentration of $10^{-7} \mathrm{M}$ also resulted in extended neutrophil survival in vitro. At $6 \mathrm{~h}$ after trypsin stimulation, the amount of early apoptotic cells becomes $21 \pm 4 \%$ lower as compared with the amount of early apoptotic cells in untreated control samples. Application of trypsin or $\mathrm{PAR}_{2}$-tcAP did not change significantly the number of neutrophils in the population of late apoptotic and necrotic cells (data not shown). Stimulation of cultured neutrophils with scrambled $\mathrm{PAR}_{2}$-tcRP (negative control) did not affect neutrophil apoptosis in vitro (Fig. 2).

\section{Effects of IFN $\gamma$ stimulation on $\mathrm{PAR}_{2}$ expression on the human neutrophil cell surface}

Previously, Nystedt et al. (39) reported that stimulation of cultured human umbilical vein endothelial cells (HUVEC) with such pro-inflammatory cytokines as TNF $\alpha$ or IL- $1 \alpha$ elevated the expression of $\mathrm{PAR}_{2}$ mRNA in these cells. IFN $\gamma$ is an immune cell produced cytokine with dual properties (pro- and anti-inflammatory) and has an ability to modulate the level of certain pro-inflammatory cytokines (TNF $\alpha$, IL-1 $\alpha$ ) (40). Therefore, we were interested whether IFN $\gamma$ stimulation may also affect $\mathrm{PAR}_{2}$ expression on human neutrophil cell surface. At $6 \mathrm{~h}$ after IFN $\gamma$ application, the amount of $\mathrm{PAR}_{2}$ positive cells increases by $45 \pm 4 \%$ as

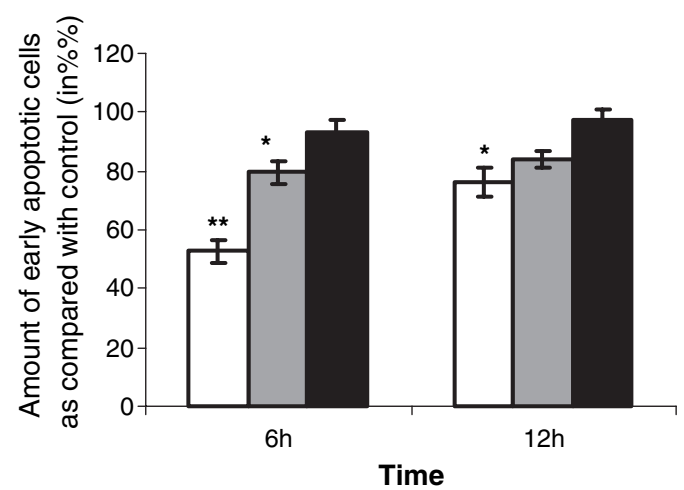

Figure 2. Agonists of proteinase-activated receptor-2 $\left(\mathrm{PAR}_{2}\right)$ prolong survival of cultured human neutrophils from healthy volunteers. No induction of apoptosis was performed. Presented data are relative where as $100 \%$ is considered the number of early apoptotic cells in untreated control samples. Application of stimuli did not change significantly the number of neutrophils in populations of late apoptotic and necrotic cells. Results are presented as an average amount of early apoptotic cells relatively to untreated control sample in per cents \pm SEM. White filled $(\square)$ boxes represent the data of PAR 2 -tcAP $\left(10^{-4} \mathrm{M}\right)$ treated; grey filled $(\square)$ boxes - trypsin $\left(10^{-7} \mathrm{M}\right)$ treated; black filled $(\square)$ boxes - PAR $_{2}$-tcRP $\left(10^{-4} \mathrm{M}\right)$ treated samples. ${ }^{*} P<0.05$, $\star * P<0.01$. Six independent experiments were performed. 
compared with unstimulated neutrophils. However, the up-regulation of the mean fluorescence intensity (MFI) remains less pronounceable (increased by $33 \pm 3 \%$ as compared with the level of untreated control) (Fig. 3a). The situation changes at $12 \mathrm{~h}$ after IFN $\gamma$ application (Fig. 3b). The number of $\mathrm{PAR}_{2}$-positive neutrophils remains very similar to the one of untreated control cells (increased by only $18 \pm 5 \%$ as compared with untreated cells). Nonetheless, the up-regulation of MFI was significant (MFI increases by $98 \pm 9 \%$ as compared with untreated control) (Fig. 3b).

\section{Simultaneous application of $\mathrm{PAR}_{2}$ agonist and interferon $\gamma$ enhances IFN $\gamma$-induced expression of Fc $\gamma$ RI (CD64) at neutrophil cell surface}

Despite granulocytes from healthy individuals are known to express CD64 at very low level, its display is induced by stimulation of neutrophils with IFN $\gamma$ (31). Therefore, we
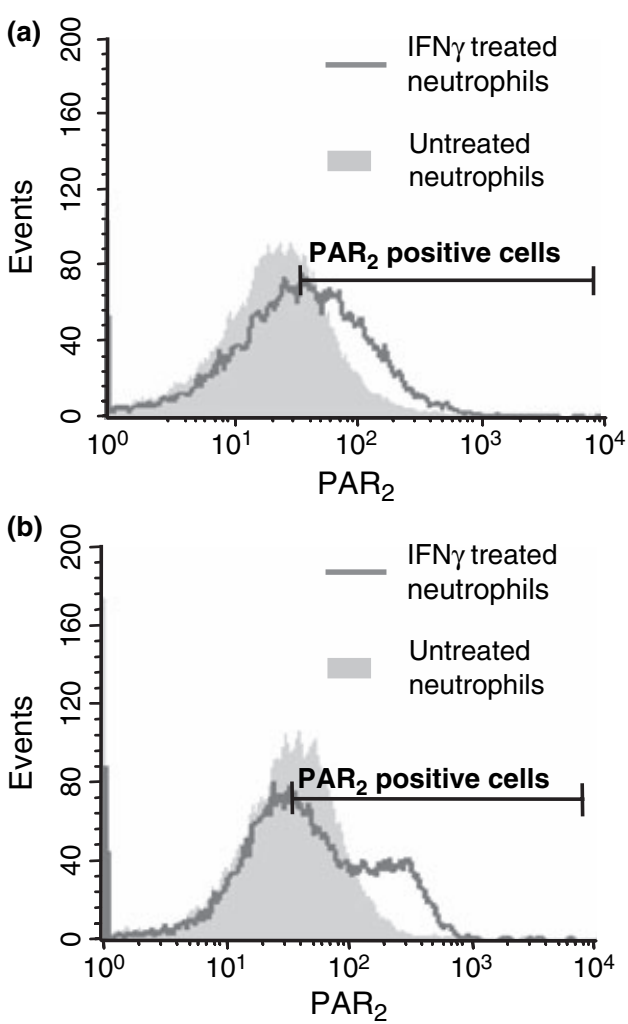

Figure 3. Interferon (IFN) $\gamma$ stimulation of human neutrophils from healthy volunteers up-regulates proteinase-activated receptor-2 $\left(\mathrm{PAR}_{2}\right)$ expression on the cell surface. Neutrophils were treated with IFN $\gamma$ $(200 \mathrm{U} / \mathrm{ml})$ and analysed at $6 \mathrm{~h}$ (a) or $12 \mathrm{~h}$ (b) after stimulation. PAR 2 positive cells are gated. Left border of the gate was always set the way that not more than $1 \%$ cells of secondary antibody control sample were included inside the gate region. The percent of $\mathrm{PAR}_{2}$-positive cells in untreated control samples was $44.9 \pm 8 \%$ for $6 h$, and $52.8 \pm 6 \%$ for $12 \mathrm{~h}$. The mean fluorescence intensity (MFI) absolute value of $P A R_{2}$ positive cells in untreated control was $52.2 \pm 11$ for 6 -h samples, and $68 \pm 6$ for 12 -h samples. Results one of three independent experiments are shown. investigated whether co-administration of $\mathrm{PAR}_{2}$ agonist and IFN $\gamma$ might enhance the known IFN $\gamma$-induced effect at CD64 display on neutrophil cell surface. Indeed, our results suggest that the treatment of human neutrophils with both agents $\left(\mathrm{PAR}_{2}\right.$-tcAP and IFN $\left.\gamma\right)$ leads to stronger up-regulation of CD64 on neutrophil cell surface than stimulation with IFN $\gamma$ alone (Fig. 4a,b). The effect of $\mathrm{PAR}_{2}$-tcAP and IFN $\gamma$ co-application reaches its maximum at $12 \mathrm{~h}$, but it already becomes significant at $6 \mathrm{~h}$ after agonist treatment (Fig. 4a). At $12 \mathrm{~h}$ after agonist application, this effect is characterized by up-regulation of MFI (increased by $41 \pm 9 \%$ as compared with cells treated with IFN $\gamma$ alone) as well as of the number of positive neutrophils (up-regulated at $90 \pm 8 \%$ as compared with neutrophils stimulated by IFN $\gamma$ alone) (Fig. 4b). Of note, co-stimulation of cultured neutrophils with IFN $\gamma$ and the scrambled $\mathrm{PAR}_{2}$-tcRP
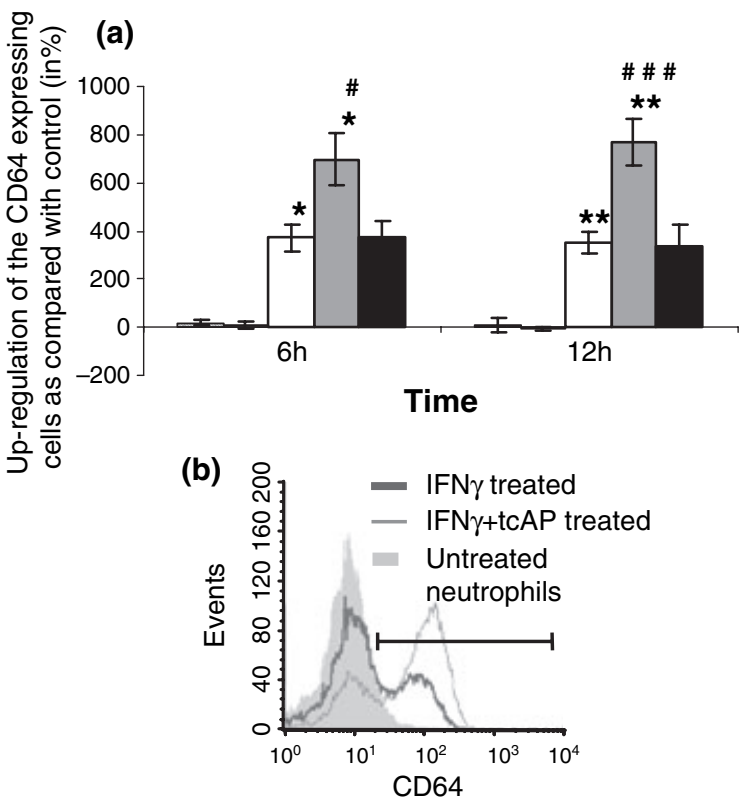

Figure 4. Simultaneous application of proteinase-activated receptor-2 $\left(\mathrm{PAR}_{2}\right)$ agonist and interferon (IFN) $\gamma$ enhances IFN $\gamma$-induced expression of CD64 expression at human neutrophil cell surface. Neutrophils were isolated from healthy volunteers. The graph (a) represents changes in CD64 cell surface expression after stimulation of cells with $\mathrm{PAR}_{2}$ tcAP $10^{-4}$ м 团; PAR ${ }_{2}$-tcRP $10^{-4}$ м $\mathbb{Q} ;$ IFN $\gamma 200 \mathrm{U} / \mathrm{ml} \square$; IFN $\gamma$ $(200 \mathrm{U} / \mathrm{ml})+\operatorname{PAR} 2_{2}-\mathrm{tCAP}\left(10^{-4} \mathrm{M}\right) \square ; \mathrm{IFN} \gamma(200 \mathrm{U} / \mathrm{ml})+\mathrm{PAR}_{2-}$ $\operatorname{tcRP}\left(10^{-4} \mathrm{M}\right)$. There were no significant changes in CD64 expression after stimulation of neutrophils with either $P A R_{2}-t c A P$ or $P A R_{2}$-tcRP (the respective columns at the graph have very small value). Results are presented as an average effect of agent application at the number of CD64-positive neutrophils as compared with untreated control samples (expressed in percents) \pm SEM. ${ }^{*} P<0.05,{ }^{*} P<0.01$. Additionally, the difference in average effects between samples stimulated with IFN $\gamma$ alone and co-stimulated with $\mathrm{PAR}_{2}$-tcAP and IFN $\gamma$ was analysed. Statistical significance of such difference is marked ${ }^{\#} P<0.05$, \#\#\# $P<0.001$. Four independent experiments were performed. Histogram shows CD64 surface expression at $12 \mathrm{~h}$ after stimuli application (b). Gated cells are CD64-positive cells. 
(negative control) did not affect neutrophil CD64 expression as compared with cells stimulated by IFN $\gamma$ alone (Fig. 4a). Stimulation of human neutrophils either by $\mathrm{PAR}_{2}$-tcAP or $\mathrm{PAR}_{2}$-tcRP alone also did not affect CD64 cell surface display (Fig. 4a).

\section{Changes of $\mathrm{PAR}_{2}$ cell surface display on neutrophils of septic patients}

Our in vitro data indicate that $\mathrm{PAR}_{2}$ agonists reduce migration of neutrophils via endothelium and also prolong neutrophil survival, therefore, potentially may promote an increase of neutrophil count in circulation. We also demonstrated that, $\mathrm{PAR}_{2}$ agonists acting together with IFN $\gamma$, significantly enhance the effect of latter at CD64 expression on neutrophils, and these results indicate the involvement of $\mathrm{PAR}_{2}$ activation in phagocytosis. Together, our data suggest that neutrophil $\mathrm{PAR}_{2}$ could be involved in the pathogenesis of human diseases, where phagocytes are in contact with pathogens in the blood flow. One of such diseases is sepsis. Therefore, we tested whether the level of neutrophil $\mathrm{PAR}_{2}$ cell surface expression might change in septic patients. Indeed, our data clearly demonstrate an increased (about $82 \%$ of up-regulation as compared with healthy volunteers) $\mathrm{PAR}_{2}$ expression on neutrophils of septic patients (Fig. 5). Thus, $\mathrm{PAR}_{2}$ may contribute to the modulation of neutrophil function during human sepsis.

\section{Discussion}

In a recent study (29), we demonstrated the ability of $\mathrm{PAR}_{2}$ agonists to up-regulate neutrophil cytokine production and motility in 3-D collagen lattices. The main goal of the present study was to further explore the role of $\mathrm{PAR}_{2}$ on neutrophils with special regard to its capability to modulate neutrophil-endothelial interactions.

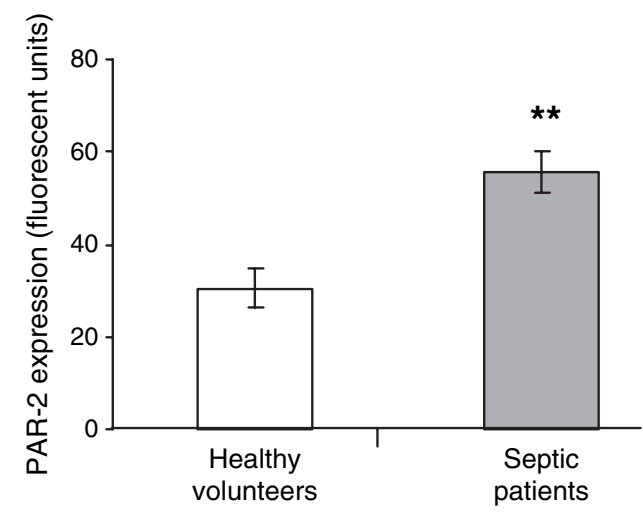

Figure 5. An increased expression of $P A R_{2}$ at the cell surface of human neutrophils from septic patients. $P A R_{2}$ display on human neutrophil cell surface is up-regulated in septic patients (19 cases) as compared with healthy volunteers (18 cases). The results are presented as average in mean fluorescence intensity units \pm SEM. ${ }^{*}{ }^{*} P<0.01$.
Our previous results were predominantly associated with a scenario in which the activation of neutrophil $\mathrm{PAR}_{2}$ took place in the extracellular matrix, i.e. after cell migration into the extravascular compartment. However, $\mathrm{PAR}_{2}$ activation on neutrophils in the vascular compartment (before transendothelial migration) cannot be completely excluded, as various natural $\mathrm{PAR}_{2}$ agonists are released within blood vessel. Among such agonists are endothelial-derived trypsin and factor VII/Xa, for example (41-43). Therefore, in the current study, we focused on the effects of $\mathrm{PAR}_{2}$ agonists, which are especially important for leukocyte biology in the blood flow. We revealed that $\mathrm{PAR}_{2}$ agonists down-regulate trans-endothelial migration of human granulocytes in vitro. Moreover, $\mathrm{PAR}_{2}$ agonists extended neutrophil life span and enhanced the IFN $\gamma$-induced Fc $\gamma$ RI (CD64) receptor expression on human neutrophils. The increase in CD64 expression is known to be associated with an enhancement of antibody-dependent cellular cytotoxicity (ADCC) and phagocytosis $(31,44)$. Consequently, this ability of $\mathrm{PAR}_{2}$ agonists to enhance IFN $\gamma$ effects strongly indicates that co-activation of $\mathrm{PAR}_{2}$ and cellular cytokine receptors may affect the progress of acute inflammatory diseases. This idea is linked to our first-time observations that $\mathrm{PAR}_{2}$ and its proteases may be involved in human diseases in vivo, as demonstrated in septic patients. Our results clearly suggest the involvement of $\mathrm{PAR}_{2}$ in neutrophil-endothelial interactions by modulating transmigration and apoptosis of human neutrophils.

Transendothelial migration of granulocytes is considered as a key step in immune response to pathogens (45). However, uncontrolled adhesion to endothelium and recruitment of neutrophils towards the site of inflammation may lead to significant tissue damage and, therefore, to poor prognosis for patient $(46,47)$. Thus, only the accurate regulation of granulocyte recruitment in extravascular compartment promotes resolution of inflammation without serious complications. Our in vitro data indicate the potential role of serine proteases and their receptors in the regulation of leukocyte transendothelial migration. Indeed, proteases (trypsin and tryptase) as well as a $\mathrm{PAR}_{2}$ activating peptide reduced the migration of human neutrophils via endothelial monolayer. Therefore, at an early stage after stimulation, $\mathrm{PAR}_{2}$ agonists and their receptor may represent an additional system which controls leukocyte recruitment and consequently modulates the intensity of immune response.

Delayed apoptosis of neutrophils migrated in extravascular space can affect the progression of inflammatory responses during infection. This effect is reached via a reduced clearance of neutrophils from the inflamed tissues and therefore via a risk of tissue injury by neutrophil granule contents (48). On the other hand, extended life of neutrophils in vascular compartment may be beneficial as it secures additional time for the development of adaptive 
immune response (31). Therefore, it was of importance to note that $\mathrm{PAR}_{2}$ agonists (trypsin as well as activating peptide) down-regulate human neutrophil apoptosis. Such an effect of $\mathrm{PAR}_{2}$ agonists on neutrophil apoptosis together with reduction of transendothelial migration may modulate the amount of human nuetrophils in circulation at early stages after stimulation.

CD64 is a high-affinity Fcy receptor, which is known to be expressed only at a very low level by neutrophils from healthy adults $(31,49)$. However, IFN $\gamma$ stimulation or bacterial infections are reported to induce the expression of CD64 on neutrophils $(50,51)$. The increase in CD64 display appears to be associated with an enhancement of ADCC and phagocytic activity of neutrophils $(31,44)$. As we showed in the current study, $\mathrm{PAR}_{2}$-tcAP stimulation alone did not markedly affect CD64 expression on neutrophil cell surface. However, co-application of $\mathrm{PAR}_{2}$ agonists together with IFN $\gamma$ enhanced the effect of latter. Our data also indicate that IFN $\gamma$ stimulation up-regulates $\mathrm{PAR}_{2}$ expression on the cell surface of isolated human neutrophils. Therefore, coordinated interactions between IFN $\gamma$ and $\mathrm{PAR}_{2}$ agonists may represent a mechanism by which IFN $\gamma$-induced protective effects could be enhanced during bacterial infection.

Sepsis in humans is known to be characterized by a state of immunosuppression associated with shutdown of neutrophil phagocytic activity and some other neutrophil functions (22). In attempt to reactivate monocyte and neutrophil immune functions, IFN $\gamma$-intravenous injections were used in clinical trials in sepsis (28). Considering the ability of $\mathrm{PAR}_{2}$ agonists to enhance one of IFN $\gamma$-induced protective effects on human neutrophils in vitro, we investigated whether cell surface expression of neutrophil $\mathrm{PAR}_{2}$ may be affected during sepsis in human patients. Our study clearly demonstrates the up-regulation of $\mathrm{PAR}_{2}$ on the neutrophil cell surface in septic patients. In accordance with these findings, the potential role of the combined action of $\mathrm{PAR}_{2}$ agonist and IFN $\gamma$ during human sepsis represents an innovative field for further investigations.

Neutrophils are the most numerous cells of blood leukocytes and represent the first line of the innate immune defense against infection. Consequently, neutrophils need to be recruited to the site of inflammation very rapidly. During disease state, molecules exist which may support or counteract this capability (52). Thus, proteases released by endothelial cells, mast cells or neutrophils themselves may be involved in the pathophysiology of cutaneous inflammation and sepsis in humans by affecting neutrophil apoptosis, transendothelial migration and $\mathrm{F} \gamma \gamma$ receptor-mediated phagocytosis. This may be of importance for the regulation of neutrophil activity during infection including septic conditions, inflammation as well as wound healing.

In conclusion, our data demonstrated that $\mathrm{PAR}_{2}$ agonists are able to enhance the protective IFN $\gamma$-induced effect on neutrophil function. Moreover, $\mathrm{PAR}_{2}$ agonists (activating serine proteases or peptides) and their receptor represent an additional system which controls neutrophil transendothelial migration and apoptosis in vitro. Thus, such system may be involved in the changes of neutrophil-endothelial interactions as well as in the enhancement of cytokineinduced effects at neutrophil functions during inflammatory or acute bacteria-induced pathologies in humans.

\section{Acknowledgements}

The work was supported by grants from the IZKF Münster (Stei2/027/06), German Research Foundation (SFB 293A14, SFB492-B13, STE 1014/2-1) (to M.S.), as well as Canadian Institutes of Health Research (Operating and Proteinases and Inflammation Network grants to M.D.H. and N.V.).

\section{References}

1 Hollenberg M D, Compton S J. International Union of Pharmacology. XXVIII. Proteinase-activated receptors. Pharmacol Rev 2002: 54: 203-217.

2 Steinhoff M, Buddenkotte J, Shpacovitch $\vee$ et al. Proteinase-activated receptors: transducers of proteinase-mediated signaling in inflammation and immune response. Endocr Rev 2005: 26: 1-43.

3 Molino M, Barnathan E S, Numerof R et al. Interactions of mast cell tryptase with thrombin receptors and PAR-2. J Biol Chem 1997: 272: 4043-4049.

4 Nystedt S, Emilsson K, Larsson A K, Strombeck B, Sundelin J. Molecular cloning and functional expression of the gene encoding the human proteinase-activated receptor 2. Eur J Biochem 1995: 232: 84-89.

5 Lourbakos A, Chinni C, Thompson P et al. Cleavage and activation of proteinase-activated receptor-2 on human neutrophils by gingipain-R from Porphyromonas gingivalis. FEBS Lett 1998: 435: 45-48.

6 Sun G, Stacey M A, Schmidt M, Mori L, Mattoli S. Interaction of mite allergens Der p3 and Der p9 with protease-activated receptor2 expressed by lung epithelial cells. J Immunol 2001: 167: 10141021.

7 Uehara A, Muramoto K, Takada H, Sugawara S. Neutrophil serine proteinases activate human nonepithelial cells to produce inflammatory cytokines through protease-activated receptor 2. J Immunol 2003: 170: 5690-5696.

8 Steinhoff M, Corvera C U, Thoma M S et al. Proteinase-activated receptor-2 in human skin: tissue distribution and activation of keratinocytes by mast cell tryptase. Exp Dermatol 1999: 8: 282-294.

9 Miike S, McWilliam A S, Kita H. Trypsin induces activation and inflammatory mediator release from human eosinophils through protease-activated receptor-2. J Immunol 2001: 167: 6615-6622.

10 Colognato R, Slupsky J R, Jendrach M, Burysek L, Syrovets T, Simmet $T$. Differential expression and regulation of protease-activated receptors in human peripheral monocytes and monocytederived antigen-presenting cells. Blood 2003: 102: 2645-2652.

11 Howells G L, Macey M G, Chinni C et al. Proteinase-activated receptor-2: expression by human neutrophils. J Cell Sci 1997: 110: 881-887.

12 Moormann C, Artuc M, Pohl E et al. Functional characterization and expression analysis of the proteinase-activated receptor- 2 in 
human cutaneous mast cells. J Invest Dermatol 2006: 126: 746-755.

13 Maurer M, Metz M. The status quo and quo vadis of mast cells. Exp Dermatol 2005: 14: 923-929.

14 Stander S, Steinhoff M. Pathophysiology of pruritus in atopic dermatitis: an overview. Exp Dermatol 2002: 11: 12-24.

15 Ossovskaya V S, Bunnett N W. Protease-activated receptors: contribution to physiology and disease. Physiol Rev 2004: 84: 579-621.

16 Noorbakhsh F, Tsutsui S, Vergnolle $\mathrm{N}$ et al. Proteinase-activated receptor 2 modulates neuroinflammation in experimental autoimmune encephalomyelitis and multiple sclerosis. J Exp Med 2006: 203: 425-435.

17 Seeliger S, Derian C K, Vergnolle N et al. Proinflammatory role of proteinase-activated receptor-2 in humans and mice during cutaneous inflammation in vivo. FASEB J 2003: 17: 1871-1885.

18 Schmidlin F, Amadesi S, Dabbagh K et al. Protease-activated receptor 2 mediates eosinophil infiltration and hyperreactivity in allergic inflammation of the airway. J Immunol 2002: 169: 5315-5321.

19 Ferrell W R, Lockhart J C, Kelso E B et al. Essential role for proteinase-activated receptor-2 in arthritis. J Clin Invest 2003: 111: 35-41.

20 Fiorucci S, Mencarelli A, Palazzetti B et al. Proteinase-activated receptor 2 is an anti-inflammatory signal for colonic lamina propria lymphocytes in a mouse model of colitis. Proc Natl Acad Sci U S A 2001: 98: 13936-13941.

21 Namkung W, Han W, Luo $X$ et al. Protease-activated receptor 2 exerts local protection and mediates some systemic complications in acute pancreatitis. Gastroenterology 2004: 126: 1844-1859.

22 Riedemann N C, Guo R F, Ward P A. The enigma of sepsis. J Clin Invest 2003: 112: 460-467.

23 McGirt $L Y$, Beck $L A$. Innate immune defects in atopic dermatitis. J Allergy Clin Immunol 2006: 118: 202-208.

24 Ellis T N, Beaman B L. Interferon-gamma activation of polymorphonuclear neutrophil function. Immunology 2004: 112: 2-12.

25 Cassatella M A, Huber V, Calzetti $F$ et al. Interferon-activated neutrophils store a TNF-related apoptosis-inducing ligand (TRAIL/Apo-2 ligand) intracellular pool that is readily mobilizable following exposure to proinflammatory mediators. J Leukoc Biol 2006: 79: 123-132.

26 Schroder K, Hertzog P J, Ravasi T, Hume D A. Interferon-gamma: an overview of signals, mechanisms and functions. J Leukoc Biol 2004: 75: 163-189.

27 Schiller M, Metze D, Luger T A, Grabbe S, Gunzer M. Immune response modifiers-mode of action. Exp Dermatol 2006: 15 331-341.

28 Vincent J L, Sun Q, Dubois M J. Clinical trials of immunomodulatory therapies in severe sepsis and septic shock. Clin Infect Dis 2002: 34: 1084-1093.

29 Shpacovitch V M, Varga G, Strey A et al. Agonists of proteinaseactivated receptor-2 modulate human neutrophil cytokine secretion, expression of cell adhesion molecules, and migration within 3-D collagen lattices. J Leukoc Biol 2004: 76: 388-398.

30 Witko-Sarsat V, Rieu P, Descamps-Latscha B, Lesavre P, HalbwachsMecarelli L. Neutrophils: molecules, functions and pathophysiological aspects. Lab Invest 2000: 80: 617-653.

31 Edwards S. Biochemistry and Physiology of the Neutrophil. New York: Cambridge University Press, 1994.

32 Shpacovitch V M, Brzoska T, Buddenkotte J et al. Agonists of proteinase-activated receptor 2 induce cytokine release and activation of nuclear transcription factor kappaB in human dermal microvascular endothelial cells. J Invest Dermatol 2002: 118: 380-385.

33 Vergnolle N, Macnaughton W K, Al-Ani B, Saifeddine M, Wallace J L, Hollenberg M D. Proteinase-activated receptor 2 (PAR2)-activating peptides: identification of a receptor distinct from PAR2 that regulates intestinal transport. Proc Natl Acad Sci U S A 1998: 95: 7766-7771.

34 Bone R C, Balk R A, Cerra F B et al. Definitions for sepsis and organ failure and guidelines for the use of innovative therapies in sepsis. The ACCP/SCCM Consensus Conference Committee. American College of Chest Physicians/Society of Critical Care Medicine. Chest 1992: 101: 1644-1655.

35 Feige U, Overwien B, Sorg C. Purification of human blood monocytes by hypotonic density gradient centrifugation in Percoll. J Immunol Methods 1982: 54: 309-315.

36 Rohnelt R K, Hoch G, Reiss $Y$, Engelhardt B. Immunosurveillance modelled in vitro: naive and memory $T$ cells spontaneously migrate across unstimulated microvascular endothelium. Int Immunol 1997: 9: 435-450.

37 Homburg $C H$, de Haas $M$, von dem Borne $A E$, Verhoeven A J, Reutelingsperger $C P$, Roos $D$. Human neutrophils lose their surface FC gamma RIII and acquire Annexin $\mathrm{V}$ binding sites during apoptosis in vitro. Blood 1995: 85: 532-540.

38 Colotta F, Re F, Polentarutti N, Sozzani S, Mantovani A. Modulation of granulocyte survival and programmed cell death by cytokines and bacterial products. Blood 1992: 80: 2012-2020.

39 Nystedt S, Ramakrishnan V, Sundelin J. The proteinase-activated receptor 2 is induced by inflammatory mediators in human endothelial cells. Comparison with the thrombin receptor. J Biol Chem 1996: 271: 14910-14915.

40 Muhl H, Pfeilschifter J. Anti-inflammatory properties of pro-inflammatory interferon-gamma. Int Immunopharmacol 2003: 3: 12471255.

41 Camerer E, Huang W, Coughlin S R. Tissue factor- and factor $\mathrm{X}$-dependent activation of protease-activated receptor 2 by factor VIla. Proc Natl Acad Sci U S A 2000: 97: 5255-5260.

42 Camerer E, Kataoka H, Kahn M, Lease K, Coughlin S R. Genetic evidence that protease-activated receptors mediate factor Xa signaling in endothelial cells. J Biol Chem 2002: 277: 16081-16087.

43 Jin E, Fujiwara M, Pan X et al. Protease-activated receptor (PAR)-1 and PAR-2 participate in the cell growth of alveolar capillary endothelium in primary lung adenocarcinomas. Cancer 2003: 97: 703713.

44 de Haas M, Vossebeld P J, von dem Borne A E, Roos D. Fc gamma receptors of phagocytes. J Lab Clin Med 1995: 126: 330-341.

45 Wagner J G, Roth R A. Neutrophil migration mechanisms, with an emphasis on the pulmonary vasculature. Pharmacol Rev 2000: 52 : 349-374.

46 Varani J, Ward P A. Mechanisms of neutrophil-dependent and neutrophil-independent endothelial cell injury. Biol Signals 1994: 3: $1-14$.

47 Lentsch A B, Ward P A. Regulation of inflammatory vascular damage. J Pathol 2000: 190: 343-348.

48 Savill J. Apoptosis in resolution of inflammation. J Leukoc Biol 1997: 61: 375-380.

49 McKenzie S E, Schreiber A D. Fc gamma receptors in phagocytes. Curr Opin Hematol 1998: 5: 16-21.

50 Goulding N J, Knight S M, Godolphin J L, Guyre P M. Increase in neutrophil Fc gamma receptor I expression following interferon gamma treatment in rheumatoid arthritis. Ann Rheum Dis 1992: 51: $465-468$.

51 Davis B H, Olsen S H, Ahmad E, Bigelow N C. Neutrophil CD64 is an improved indicator of infection or sepsis in emergency department patients. Arch Pathol Lab Med 2006: 130: 654-661.

52 Steinhoff M, Griffiths C M E, Church M K, Luger T A. Inflammation. In: Burns T, Breathnach S, Cox N, Griffiths C, eds. Rook's Textbook of Dermatology, 7th edn. Oxford: Blackwell Publishing Ltd., 2004. 